\title{
Proceeding
}

Supplementary Issue: Spring Conferences of Sports Science. Costa Blanca Sports Science Events, 14-15 June 2019. Alicante, Spain.

\section{Self-physical and emotional perception in rhythmic gymnastics for drop out}

\author{
FRANCESCA D'ELIA ${ }^{1} \triangle$, RICCARDO IZZO², BARBARA SENATORE ${ }^{1}$ \\ 1 University of Salerno, Italy \\ 2University of Urbino, Italy
}

\begin{abstract}
In rhythmic gymnastics, very young athletes undertake a competitive activity and support workloads of four or five hours, almost unthinkable for such small girls, yet to achieve maximum results it is necessary to start at a young age and work hard. The purpose of the study is to study, in different groups of athletes (3-7 years, 8-12 years, 13-18 years) of rhythmic gymnastics, how they face emotionally and physically the physical and emotional workloads and especially if you find physical and mental well-being. The method of the study is qualitative/quantitative and the administration of 10 questions: 5 to identify the physical self-perception and 5 for the emotional one, is done anonymously. The data shows that the self-perception for physical performance is average (positive or negative and put the percentage) and the self-perception for motivation performance is average (positive or negative) and put the percentage. This data is significant for the perceptive state of the athletes to whom it is necessary to refer in order to realistically face the problem. Given the data and their significance, the study must be deepened with a more significant and detailed sample of data. Keywords: Self-perception; Motivation; Young athletes.
\end{abstract}

\section{Cite this article as:}

D'Elia, F., Izzo, R., \& Senatore, B. (2019). Self-physical and emotional perception in rhythmic gymnastics for drop out. Journal of Human Sport and Exercise, 14(4proc), S1071-S1079. doi:https://doi.org/10.14198/ihse.2019.14.Proc4.70

\footnotetext{
Corresponding author. University of Salerno, Italy.

E-mail: fdelia@unisa.it

Supplementary Issue: Spring Conferences of Sports Science. Costa Blanca Sports Science Events, 14-15 June 2019. Alicante, Spain.

JOURNAL OF HUMAN SPORT \& EXERCISE ISSN 1988-5202

(c) Faculty of Education. University of Alicante

doi:10.14198/jhse.2019.14.Proc4.70
} 


\section{INTRODUCTION}

Often during the annual planning and scheduling of objectives, of the various sessions of team sports, very important aspects (Raiola, 2015b; Altavilla et al., 2015b; Valentini et al., 2018), erroneously considered secondary, including the psychological aspect, are overlooked.

In a sport such as rhythmic gymnastics, in order to achieve the best performance it is necessary to start at a young age and work hard, but this is not always enough because it is a fairly selective sport (D'Isanto et al., 2019).

When it comes to motivation, you never know where to start. There are technicians in this sport who believe that motivation is an indefinable gift of nature, so an athlete either owns it or not.

To think that athletes want or do not want to do something "by nature" or that only the coach can give them the motivation to do it is not only an illusory expectation, but it can be completely negative.

Often athletes who oppose the technician's indications are strongly motivated to sport; in fact, they are only not motivated to accept the structures and methods imposed by their coach (Invernizzi et al., 2019).

The phenomenon of "Drop out", i.e. the early abandonment of sport, is a big problem especially for sports such as rhythmic gymnastics where you have to try to get everything right away (Altavilla et al., 2015a).

The purpose of the study is to investigate, in different groups of athletes (3-7 years, 8-12 years, 13-18 years) of rhythmic gymnastics (Barbara, 2018; Senatore et al., 2019a-b), how they face emotionally and physically the physical and emotional workloads and, above all, if you find physical and mental well-being (Severino et al., 2019).

\section{METHOD}

For this research the case study was chosen because it allows to place emphasis on the detailed contextual analysis of a limited number of events or conditions and their relationships.

The construction of the sample took place through a non-probabilistic sampling procedure subdividing the groups by age (3-7 years; 8-12 years; $13-18$ years).

The method of the study is qualitative/quantitative, administering through a special online platform a questionnaire of 10 questions: 5 to identify the physical self-perception and 5 for the emotional one, in total anonymity so as not to incur in false data.

The study was subjected to rhythmic gymnastics athletes of different age groups.

The study involved 28 athletes in 3 groups: 12 girls aged between 3 and 7 years, athletes aged between 8 and 12 years and 8 other girls aged between 13 and 18 years.

The contents are established a priori, standardization in reference to the uniformity of the stimuli offered and high structuring as the respondent cannot come out off track predetermined. 
To avoid external influences in the respondents was decided to administer the questionnaire through the online platform Google drive "forms".

In order to assess the quality of the instrument, a pre-test with similar characteristics was carried out prior to administration.

Attention has allowed to evaluate the effectiveness of the tool by identifying some distortions arising from the articulation of the questionnaire.

The pre-test suggested important methodological indications to refine the specification of the most relevant concepts of the research, for their operational definition and, therefore, for the final drafting of the questionnaire: for example, some indicators were revised, eliminating those semantically redundant or invalid compared to the indicated size.

The main topic of the questionnaire is perception, we first investigated the physical and then the emotional perception.

\section{RESULTS}

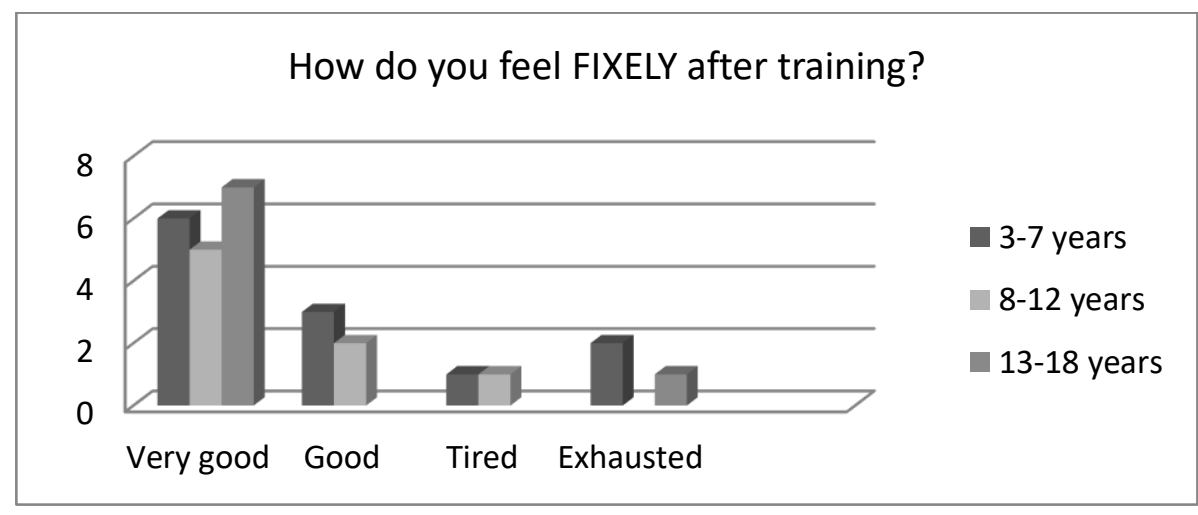

Figure 1. Perception fixely after training.

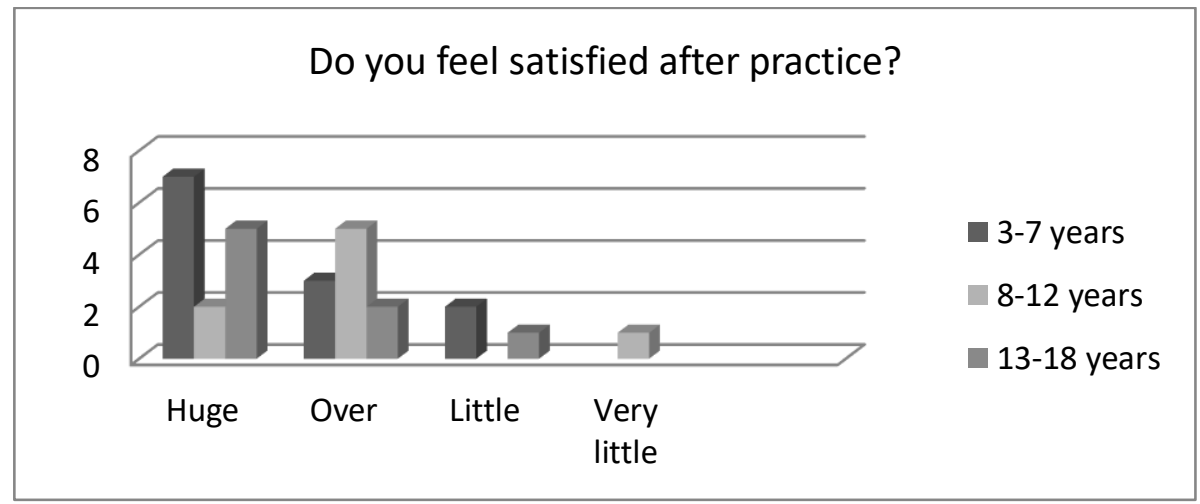

Figure 2. Perception satisfaction after practice. 


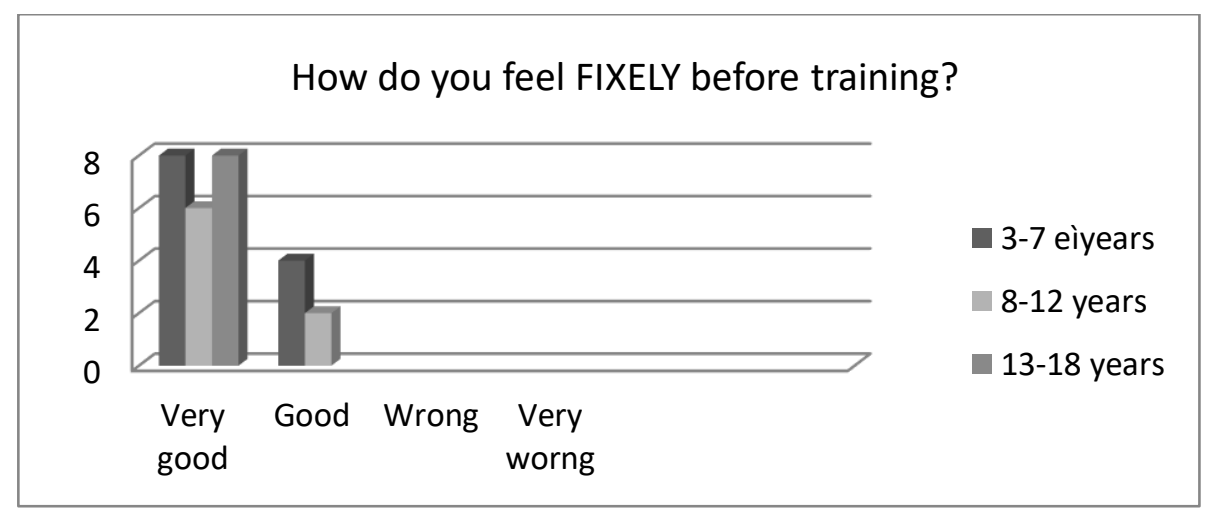

Figure 3. Perception fixely before training.

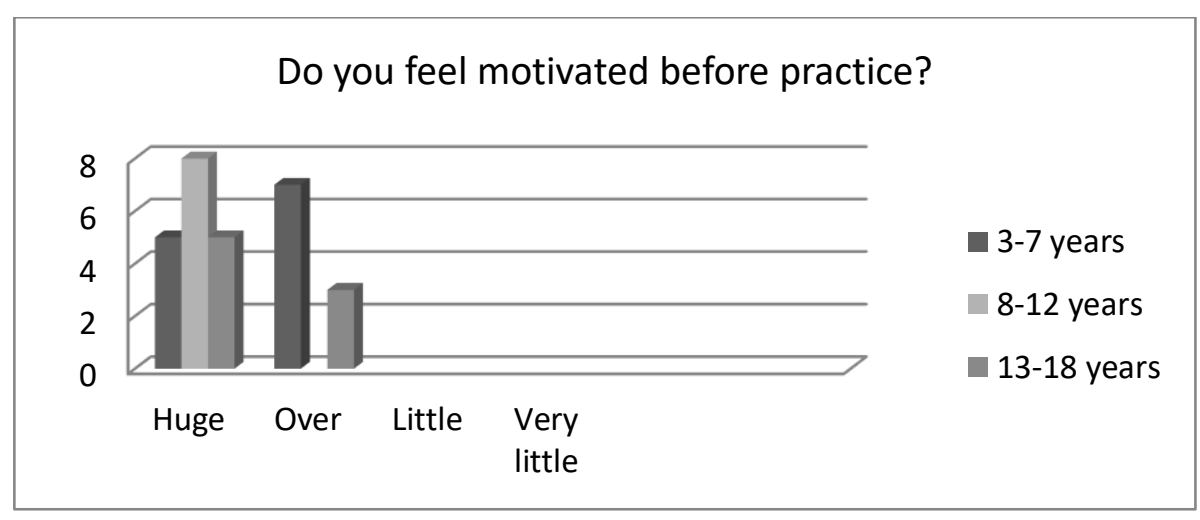

Figure 4. Perception motivation before training.

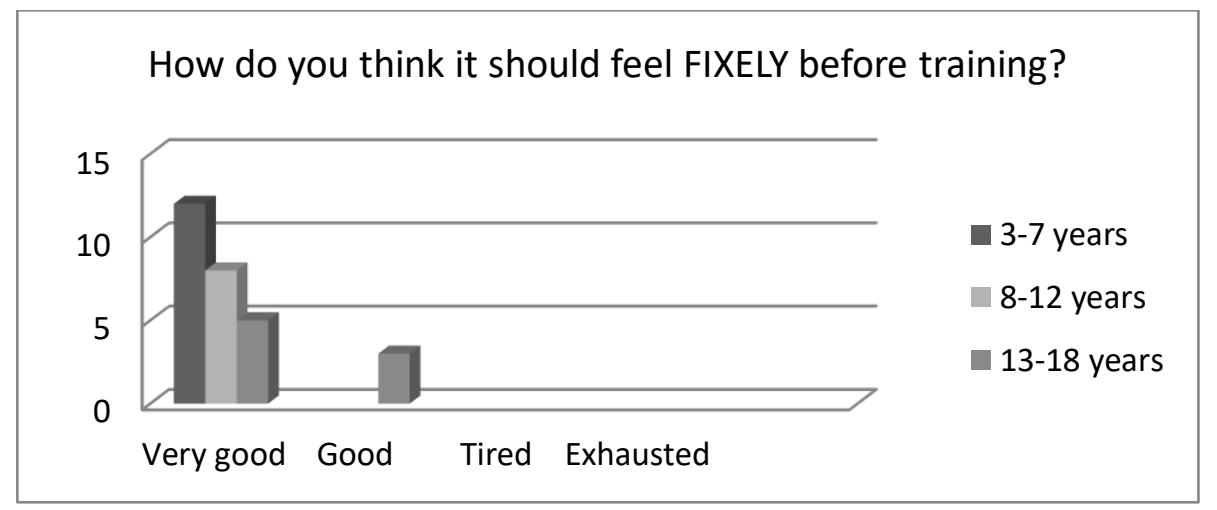

Figure 5. Thinking about fixely before training. 


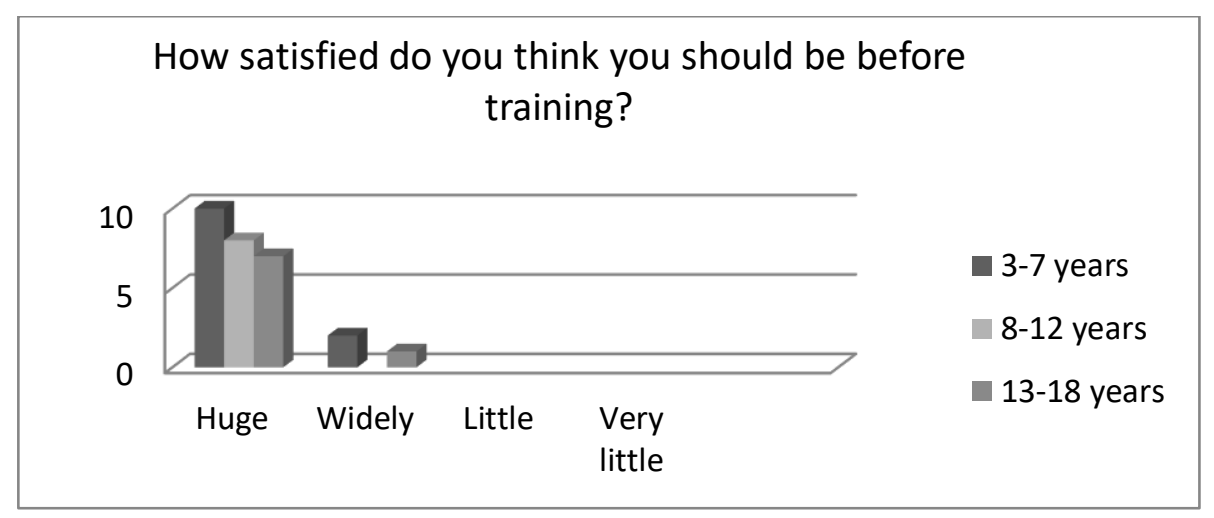

Figure 6 . Thinking about satisfaction before training.

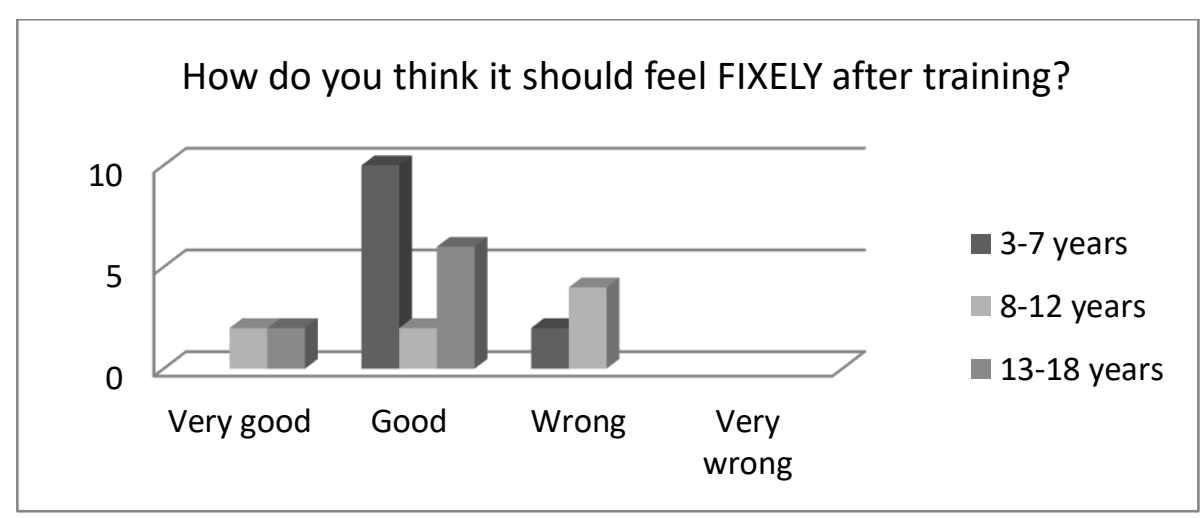

Figure 7. Thinking about fixely after training.

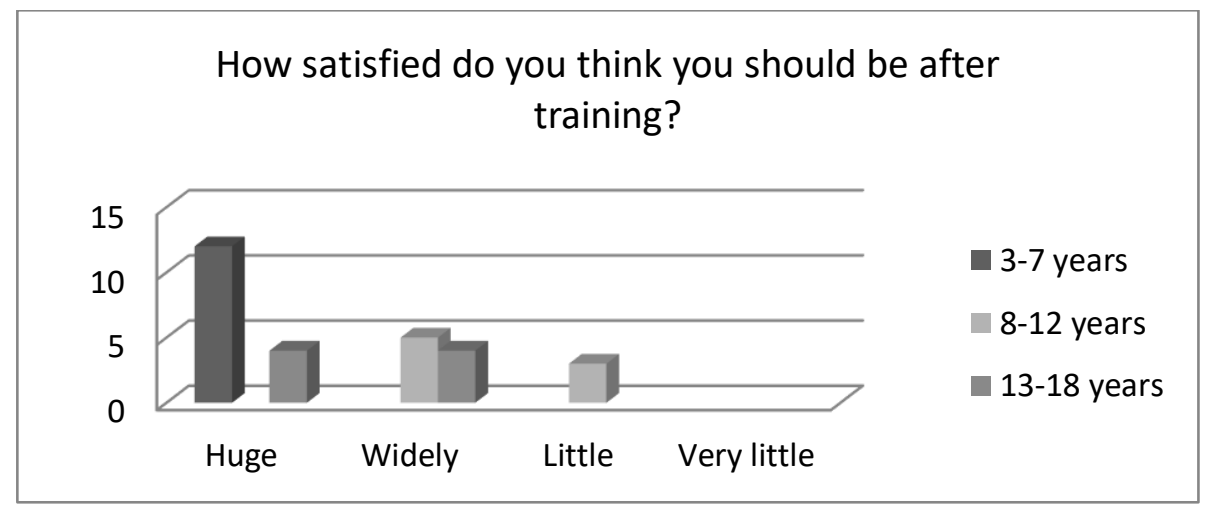

Figure 8. Thinking about satisfaction after training. 


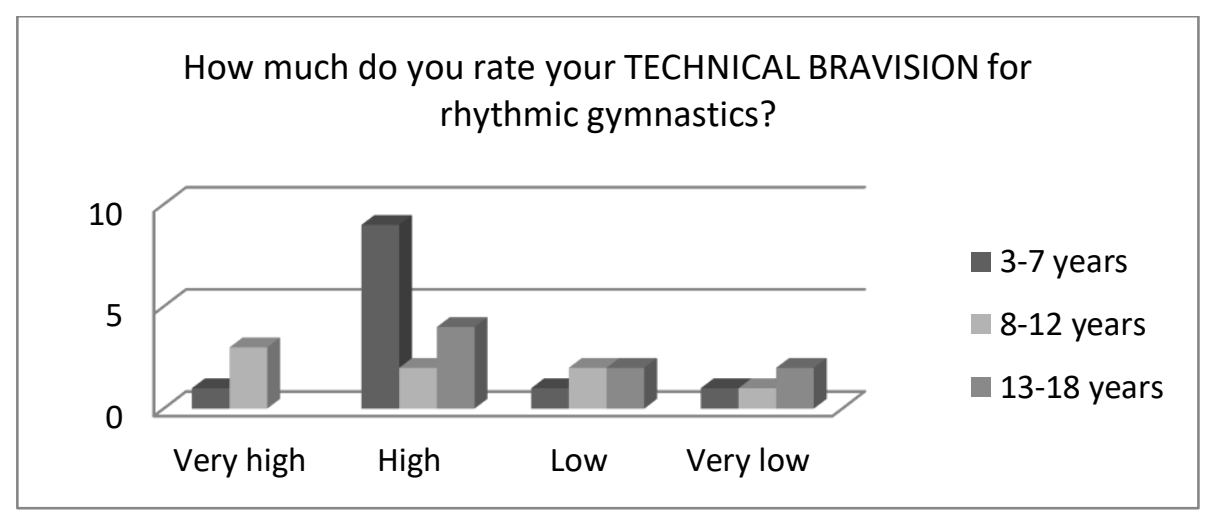

Figure 9. Skill rate.

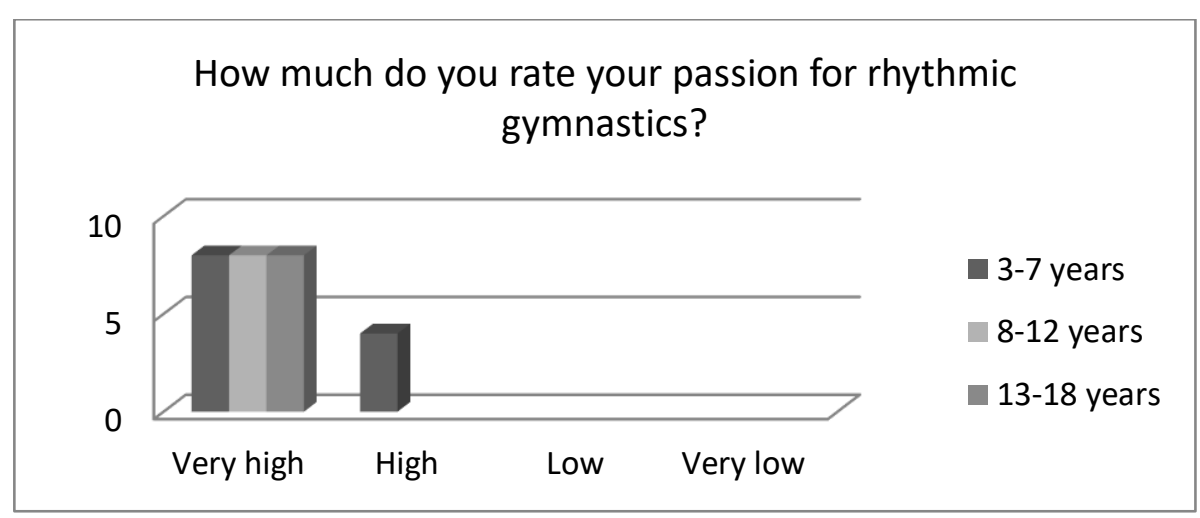

Figure 10. Passion rate.

Table 1. Correlation between the levels of physical and emotional perception (3-7 years)

\begin{tabular}{|c|c|c|c|c|}
\hline & & & VAR00001 & VAR00004 \\
\hline \multirow{2}{*}{ Tau_b by Kendall } & VAR00001 & $\begin{array}{c}\text { Correlation } \\
\text { coefficient } \\
\text { Sign. (two-tailed) } \\
\mathrm{N}\end{array}$ & $\begin{array}{c}1.000 \\
10\end{array}$ & $\begin{array}{c}.707^{*} \\
.025 \\
10\end{array}$ \\
\hline & VAR00004 & $\begin{array}{c}\text { Correlation } \\
\text { coefficient } \\
\text { Sign. (two-tailed) } \\
\mathrm{N}\end{array}$ & $\begin{array}{c}.707^{*} \\
.025 \\
10\end{array}$ & $\begin{array}{c}1.000 \\
10\end{array}$ \\
\hline
\end{tabular}

*. The correlation is significant at 0.05 (two-tailed) level. 
Table 2. Correlation between the levels of physical and emotional perception (8-12 years)

\begin{tabular}{|ccc|c|c|}
\hline & & & VAR00002 & VAR00005 \\
\hline & VAR00002 & $\begin{array}{c}\text { Correlation } \\
\text { coefficient } \\
\text { Sign. (two-tailed) } \\
\text { Tau_b by Kendall }\end{array}$ & 1.000 & $.630^{*}$ \\
\cline { 2 - 5 } & VAR00005 & $\begin{array}{c}\text { Correlation } \\
\text { coefficient } \\
\text { Sign. (two-tailed) } \\
N\end{array}$ & 10 & .032 \\
& & $.630^{*}$ & 10 \\
\hline
\end{tabular}

*. The correlation is significant at 0.05 (two-tailed) level.

Table 3. Correlation between the levels of physical and emotional perception (13-18 years)

\begin{tabular}{|c|c|c|c|c|}
\hline & 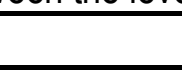 & & VAR00003 & VAR00006 \\
\hline \multirow{5}{*}{ Tau_b by Kendall } & \multirow{2}{*}{ VAR00003 } & & 1.000 & \\
\hline & & Sign. (two-tailed) & & .236 \\
\hline & \multirow{3}{*}{ VAR00006 } & $\begin{array}{l}\text { Correlation } \\
\text { coefficient }\end{array}$ & .378 & 1.000 \\
\hline & & Sign. (two-tailed) & 236 & \\
\hline & & $\mathrm{N}$ & 10 & 10 \\
\hline
\end{tabular}

\section{DISCUSSION}

This research stems from the desire to deepen knowledge about the perception of athletes and what drives them to abandon.

From the data obtained from the questionnaire administered, there is an average positive physical selfperception in all age groups analysed and it seems possible not to attribute to it the motivation to abandon this sport.

Unlike the results on emotional self-perception where we can see not always positive results.

There is a good motivation before training, a possible symptom of a sporting choice not because one's own choice, especially in the age group of 3-7 years and 8-12 years, differently from the age group of 13-18 years where the motivation is high, about $90 \%$.

Another aspect to consider, in the search for motivation to abandon, is the clearly positive result about the recreational aspect that should have the workouts (D'Isanto, 2016), and in the absence of fun in them can lead to abandonment.

Tables 1 and 2 show a strong correlation between the two levels (physical and emotional) of perceived wellbeing, therefore these are perceived in a similar way by groups of 3-7 and 8-12 years old. 
Table 3 shows a low correlation between the two levels (physical and emotional), therefore these are not perceived in a similar way by the group of 13-18 years old.

With the Kendall Tau Test we tried to establish if the level of correlation and therefore of self-perception (Raiola, 2015a) (physical and emotional), in the different ages, was similar (only for the age groups 3-7 and 8-12 years).

\section{CONCLUSION}

We speak of a drop-out in sport to indicate the early, and often permanent, abandonment of sport, especially by girls in adolescence.

This is a worrying phenomenon and difficult to interpret.

The absence of the recreational-motor component, the lack of fun and the onset of boredom, the psychological pressure of the performance and the winning expectations from the surrounding environment, conflicts and guilty judgments can generate a feeling of incompetence and fear of getting involved as a result of any failures, as well as experiences of anxiety and stress, preventing him from dealing with the experience in a positive way and, in fact, causing the loss of interest in the activity carried out (Burnout) and the interruption of the sport (drop-out), which is experienced as a failure and, consequently, as a source of insecurity.

The premature abandonment of sport has negative effects on the growth of the athlete on a physical, psychological and social level, as it leads to an increase in sedentary lifestyles (D'Isanto, 2019).

Given the data and their significance, the study should be deepened with a more significant and detailed sample of data.

\section{REFERENCES}

Altavilla, G., Furino, F., Di Palmo, M., Raiola, G. (2015a) The child hypokinetic and the overtrained, Sport Science, 8, pp. 72-74.

Altavilla, G., Furino, F., Marika, D.P., Raiola, G. (2015b) Physical skills, sport learning and socio-affective education, Sport Science, 8, pp. 44-46.

Barbara, S., Francesca, D. (2018) Rhythmic gymnastics and dyslexia: A two-year preliminary case study, Journal of Physical Education and Sport, 18, art. no. 320, pp. 2122-2126.

D'Isanto, T. (2016) Pedagogical value of the body and physical activity in childhood, Sport Science, 9, pp. 13-18.

D'isanto, T. (2019) Physical and sport education between Italian academic system and European Research Council structure panel, Journal of Human Sport and Exercise, 14, pp. S66-S76. https://doi.org/10.14198/ihse.2019.14.proc1.08

D'Isanto, T., D'Elia, F., Raiola, G., Altavilla, G. (2019)Assessment of sport performance: Theoretical aspects and practical indications, Sport Mont, 17 (1), pp. 79-82.

Invernizzi, P.L., Crotti, M., Bosio, A., Cavaggioni, L., Alberti, G., Scurati, R. (2019)Multi-teaching styles approach and active reflection: Effectiveness in improving fitness level, motor competence, enjoyment, amount of physical activity, and effects on the perception of physical education lessons in primary school children, Sustainability (Switzerland), 11 (2). https://doi.org/10.3390/su11020405 
Raiola, G. (2015a) Inclusion in sport dance and self perception Sport Science, 8, pp. 99-102.

Raiola, G. (2015b) Sport skills and mental health, Journal of Human Sport and Exercise, 10 (Specialissue), pp. S369-S376. https://doi.org/10.14198/ihse.2015.10.Proc1.27

Senatore, B., Valentini, M., Federici, A., D'elia, F. (2019a)Pilot case study on rhythmic gymnastics and dyslexia, Journal of Human Sport and Exercise, 14 (Proc2), pp. S198-S205. https://doi.org/10.14198/ihse.2019.14.proc2.06

Valentini, M., Riccardi, F., Raiola, G., Federici, A. (2018) Educational research: Motor area and relational area during children's personality development, Journal of Physical Education and Sport, 18, art. no. 327, pp. 2157-2174. 